University of Nebraska - Lincoln

DigitalCommons@University of Nebraska - Lincoln

Publications, Agencies and Staff of the U.S.

Department of Commerce

U.S. Department of Commerce

2005

Relating Results of Chronic Toxicity Responses to Population-

Level Effects: Modeling Effects on Wild Chinook Salmon

Populations

Julann A. Spromberg

NOAA

James P. Meador

NOAA, james.meador@noaa.gov

Follow this and additional works at: https://digitalcommons.unl.edu/usdeptcommercepub

Part of the Environmental Sciences Commons

Spromberg, Julann A. and Meador, James P., "Relating Results of Chronic Toxicity Responses to Population-Level Effects: Modeling Effects on Wild Chinook Salmon Populations" (2005). Publications, Agencies and Staff of the U.S. Department of Commerce. 218.

https://digitalcommons.unl.edu/usdeptcommercepub/218

This Article is brought to you for free and open access by the U.S. Department of Commerce at DigitalCommons@University of Nebraska - Lincoln. It has been accepted for inclusion in Publications, Agencies and Staff of the U.S. Department of Commerce by an authorized administrator of DigitalCommons@University of Nebraska - Lincoln. 


\title{
Relating Results of Chronic Toxicity Responses to Population-Level Effects: Modeling Effects on Wild Chinook Salmon Populations
}

\author{
Julann A. Spromberg and James P. Meador* \\ Environmental Conservation Division, Northwest Fisheries Science Center, National Marine Fisheries Service, NOAA, 2725 Montlake \\ Boulevard East, Seattle, Washington 98112, USA
}

(Received 22 February 2004; Accepted 23 June 2004)

\begin{abstract}
Standard toxicity tests assess the physiological responses of individual organisms to exposure to toxic substances under controlled conditions. Time and space restrictions often prohibit the assessment of population-level responses to a toxic substance. Compounds affecting various toxicity endpoints, such as growth, fecundity, behavior, or immune function, alter different demographic traits and produce different impacts on the population. Chronic effects of immune suppression, reproductive impairment, and growth reduction were examined using life history models for Chinook salmon (Oncorhynchus tshawytscha). Modeled immune suppression acted through reductions in age-specific survival, with first- and secondyear survival producing the greatest changes in the population growth rate $(\lambda)$. A $10 \%$ reduction in various reproductive parameters all produced a similar $\lambda$, but different sensitivity and stable age distributions. Growth reduction models incorporated effects to both survival and reproduction and produced additive effects. Overall, model output indicated that for Chinook salmon, alteration of first-year survival has the greatest relative impact on $\lambda$. Results support the importance of linking toxicity endpoints to the demographic traits that they influence and help generate toxicity tests that are more relevant for the species. Life history modeling provides a useful tool to develop testable hypotheses regarding specific and comparative population-level impacts.
\end{abstract}

Keywords: Life history modeling Chronic toxicity Chinook salmon Population-level effects

\section{INTRODUCTION}

The primary purpose of listing a species under the Endangered Species Act (ESA) is to conserve the genetic diversity of the species, recover populations to sustainable levels, and to ensure high-quality habitat to support the population. Declining populations may be listed under the ESA as evolutionarily significant units if they are reproductively isolated and represent an important part of the species' genetic diversity (Waples 1991). Factors known to contribute to population decline include habitat degradation and loss, overharvest, and chemical insult. Each of these factors has contributed to the decline of the ESA-listed Pacific salmon, including the Chinook salmon (Oncorhynchus tshawytscha). Compliance with regulatory measures such as the Clean Water Act has prevented most acutely toxic chemical insults, with the exception of accidental spills. Despite this progress, aquatic biota are often exposed to low concentrations of toxic chemicals for extended periods of time. The U.S. Geological Survey (USGS 1999) has identified 23 pesticides in urban streams around the Puget Sound (WA, USA) watershed that provide habitat for ESA-listed salmonids, and ongoing studies have documented the presence of PCBs, PAHs, and metals in Puget Sound marine sediments (McCain et al. 1990; Johnson et al. 1993; Landahl and Johnson 1993; Varanasi et al. 1993; Johnson et al. 1997). Although laboratory testing may reveal physiological effects from these chronic exposures, less is known about population-level effects in a

* To whom correspondence may be addressed james.meador@noaa.gov natural setting. This leaves a large gap in the protection of declining species.

The physiological effects of toxic substances on individual organisms can be determined using standardized laboratory toxicity tests. Since the population-level effects of these compounds are much more difficult to assess due to the time and space limitations required to conduct appropriate experiments, the laboratory toxicity test results are often applied to population-level assessments. Consequently, questions arise regarding the ecological significance of laboratory results. Laboratory tests are generally short and highly controlled to accurately estimate physiological response, but may not directly relate to population events in a natural setting. For instance, if two fish species have the same physiological response and chemical sensitivity, toxicity test results propose that both species will respond similarly to environmental exposure. However, differences in life history strategies (i.e., life stage survival rates, time to reproductive maturity, and reproductive frequency) profoundly alter population persistence (Schaaf et al. 1993; Caswell 2001), and therefore the same response at the individual level does not necessarily equate to the same response at the population level. This divergence raises concerns for interpreting the significance of a toxicity test measurement endpoint to population-level effects.

The models discussed in this paper characterize chronic toxicity endpoints related to immune function, reproduction, and somatic growth. Immune suppression directly relates to individual health and can alter survival rates. Reproductive toxicity effects can alter the reproductive contribution 
of individuals and age groups within a population. Inhibition of somatic growth potentially decreases both survival and reproductive contribution. Through these pathways, the toxicity endpoint categories relate directly to alterations in life history parameters. They also represent active areas of toxicological research. The objective of this project was to determine how various sublethal toxic impacts may translate to population-level effects in light of the life history strategy of the focal species. We chose ocean-type Chinook salmon as the focal species because of its ESA listing and known exposure to chemical contaminants in some areas of Puget Sound. The overall goal of the project was to gauge potential population-level impacts due to contaminant exposure and to compare different biological responses. Information gained here will guide further research activities and actions to protect endangered salmonids and ecosystem function.

\section{Immune toxicity scenarios}

Chinook salmon exposed to environmental concentrations of contaminants experience immune suppression and increased susceptibility to disease. Some effects include suppression of immunological memory due to $\mathrm{PAH}$ and $\mathrm{PCB}$ exposure as measured by primary and secondary plaqueforming cell (PFC) responses (Arkoosh et al. 1994). Compromised immune function was investigated in juvenile Chinook collected from urban and nonurban estuaries in Puget Sound that were exposed to Listonella anguillarum (Vibrio anguillarum) in the laboratory (Arkoosh et al. 1998). Fish from the urban estuary were more susceptible than fish from the nonurban estuary to mortality from L. anguillarum exposure during the juvenile stage. Significant differences in mortality were seen even 2 months after removal from the contaminated areas, suggesting that individuals exposed to chemical contaminants may have a higher predisposition to infection. Repetition of the project in a controlled setting exposed saltwater-adapted juvenile Chinook to contaminants representative of Puget Sound sediment followed by exposure to L. anguillarum. The juveniles experienced greater mortality from L. anguillarum after chemical exposure (Arkoosh et al. 2001). It is not clear whether juvenile immune suppression leads to effects at later ages or if open ocean chemical exposures result in sufficient tissue concentrations to trigger immune suppression. A recent laboratory study by Milston et al. (2003) observed humoral immunosuppression 1 year after a 1 -h exposure followed a month later by a 2-h exposure of Chinook embryos to sublethal concentrations of dichlorodiphenyldichloroethylene.

\section{Reproductive toxicity scenarios}

Exposure to contaminants has been shown to alter reproductive endpoints such as fecundity, egg survival, spawning behavior, and time to reproductive maturity in affected fish. Chen et al. (1986) fed rainbow trout PCB-contaminated diets at $0.3 \mu \mathrm{g} / \mathrm{g}$ body weight for 6 months and observed a significant suppression of vitellogenin production. Ankley et al. (1991) observed an inverse relationship between maternally transferred PCBs in eggs and hatching success in Chinook salmon at approximately 100 pg TCDD-EQ/g egg. Lower gonadal/somatic index and hormone levels have been observed in rock sole (Pleuronectes bilineatus) and English sole (Pleuronectes vetulus) from PCB-contaminated sites (Johnson et al. 1998). The same paper also showed higher fecundity but smaller egg size and lower fertilization rates in fish from the heavily PAH-contaminated site, Eagle Harbor (Johnson et al. 1998). One cause could be selection for individuals with higher fecundity due to the imposed higher mortality rates. Sunfish (Lepomis auritus) populations in a river receiving bleached kraft mill effluent exhibit a shift to higher average age and larger average size, suggesting a failure in recruitment after this long-term exposure (Adams et al. 1992). In addition, concern has been raised about some environmental pollutants that exhibit hormonal activity and cause disruption of the reproductive endocrine system or directly affect gamete viability (Kime 1999).

\section{Growth inhibition scenarios}

Many compounds, including metals and organics, inhibit somatic growth in fish (Roch and McCarter 1984; Finlayson and Verrue 1985; Glubokov 1990; Stein et al. 1995; Hansen et al. 2002). Size has been linked to age-specific survival rates, age at reproductive maturity, fecundity, and spawning success (Bagenal 1969; Roff 1984; Sigler and Sigler 1987; Wootton 1992; Koztowski 1996). Therefore, alterations in somatic growth may affect life history traits, including agespecific survival and reproductive traits. However, these impacts may be reduced when sufficient food is available. Chinook salmon fry exposed to mixtures of copper, cadmium, and zinc at environmentally relevant concentrations for 21 weeks showed significant effects on growth, but not survival (Roch and McCarter 1984).

\section{METHODS}

\section{General models}

The investigation of population-level responses to various toxic impacts used projection matrix models. Projection matrix methods followed Caswell (2001) for calculating the transition matrix (Figure 1) from the life history graph and determining the population growth rate and stable age distribution, and for conducting sensitivity and elasticity analyses.

Individuals within a population exhibit various growth, reproduction, and survivorship rates depending on their developmental or life history stage or age. These age-specific characteristics are depicted in the life history graph (Figure 1) in which transitions are depicted as arrows. The matrix elements represent transitions corresponding to reproductive contribution or survival, located in the top row and the subdiagonal of the matrix, respectively. The survival transitions in the life history graph were incorporated into the $n \times n$ square matrix $(A)$ by assigning each age a number ( 1 through $n$ ), and each transition from stage $i$ to stage $j$ becomes the element $a_{i j}$ of matrix $A$ ( $i=$ row, $j=$ column) and represent the proportion of the individuals in each age passing to the next age as a result of survival. The reproductive element $\left(a_{1 j}\right)$ gives the number of offspring that hatch per individual in the contributing stage, $j$. The reproductive element value incorporates fecundity, fertilization success, hatch success, number of spawning events per year, fraction of females in the age that are sexually mature, and the fraction of females in each age. Reproduction in the model occurs at the end of each iteration (year) following all other survival events.

A life history model was constructed for ocean-type Chinook salmon (O. tshawytscha) with a maximum age of 5 years. Transition values were determined from literature data on survival and reproductive characteristics (Healey 
A

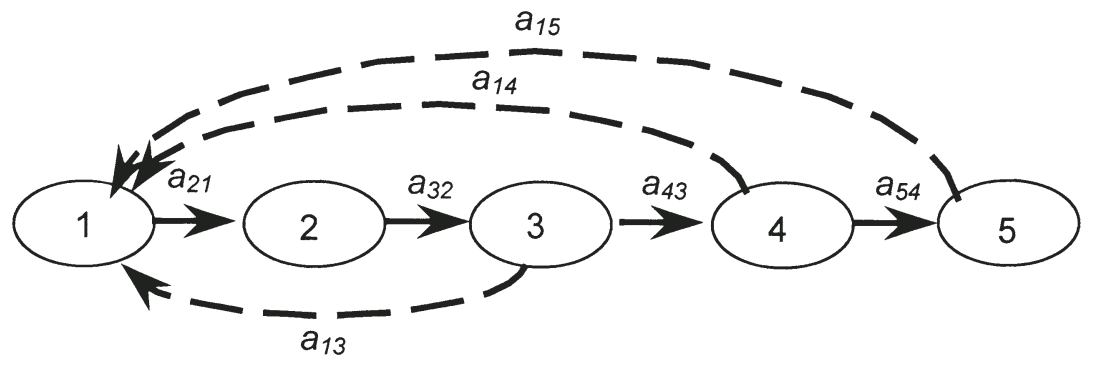

$\mathrm{B} \quad \mathrm{A}=\left[\begin{array}{lllll|}\hline 0 & 0 & \mathrm{R} 3=a_{13}{ }^{*} \mathrm{RT} & \mathrm{R} 4=a_{14}{ }^{*} \mathrm{RT} & \mathrm{R} 5=a_{15}{ }^{*} \mathrm{RT} \\ \mathrm{S} 1=\mathrm{a}_{21}{ }^{*} \mathrm{ST} 1 & 0 & 0 & 0 & 0 \\ 0 & \mathrm{~S} 2=a_{32}{ }^{*} \mathrm{ST} 2 & 0 & 0 & 0 \\ 0 & 0 & \mathrm{~S} 3=a_{43}{ }^{*} \mathrm{ST} 3 & 0 & 0 \\ 0 & 0 & 0 & \mathrm{~S} 4=a_{54}{ }^{*} \mathrm{ST} 4 & 0\end{array}\right.$

C Loop 3
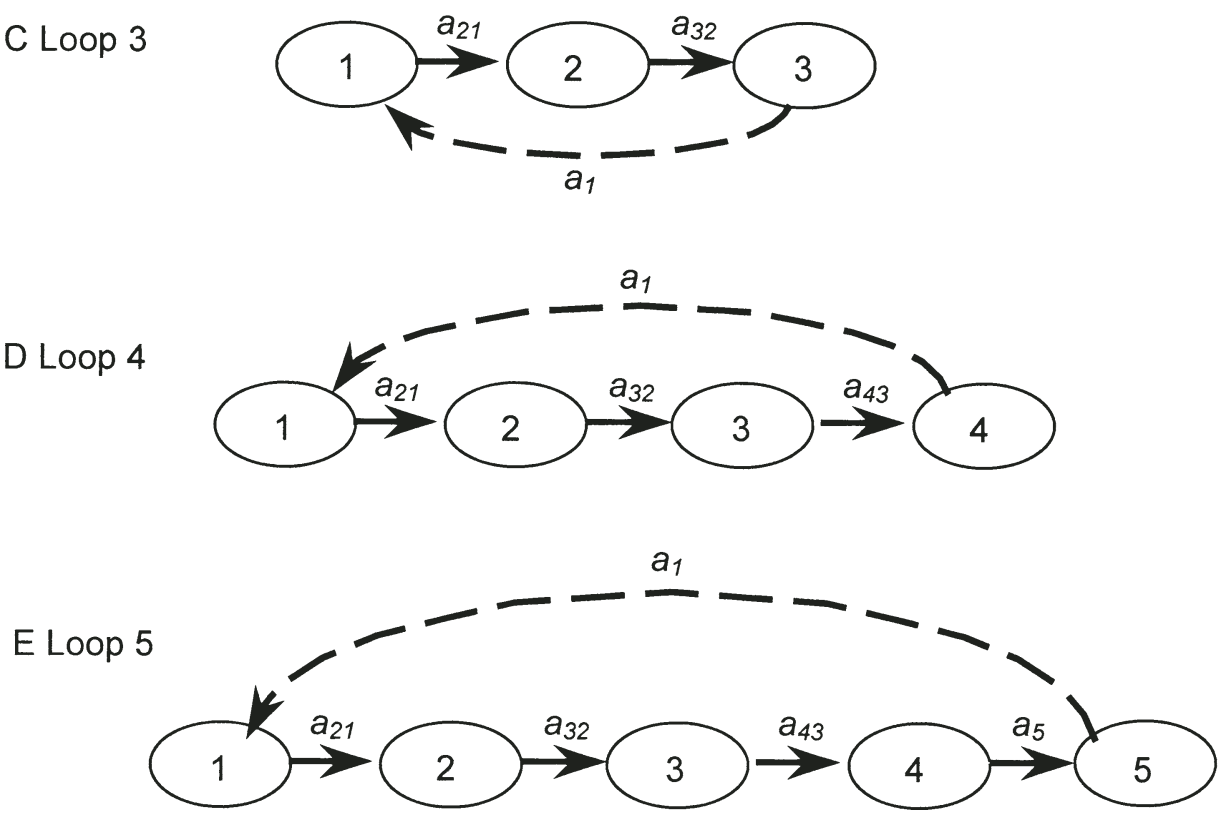

Figure 1. (A) Life history graphs and transition matrix for Chinook salmon. The life history graph for a population with age-specific reproduction with the ages labeled 1 through 5 and each transition element labeled according to the matrix position, $a_{i j}, i$ row, $j$ column. Dashed lines represent reproductive contribution and solid lines represent survival transitions. (B) The transition matrix for the life history graph depicted in (A) with reproductive (RTi) and survival (STi) toxicity multipliers. The life history graph (A) can be broken down into 3 loops (C-E) according to age-specific reproduction, which will be referred to as reproductive pathways.

and Heard 1984; Fast et al. 1988; Roni and Quinn 1995; Ratner et al. 1997; PSCCTC 2002). It is assumed that no overall shifts in energy balance occur since the models represent low-level chronic impacts. Therefore, effects can be treated as independent responses such that, for example, an impact on immune function and the corresponding physiological compensation will not result in energy trade-offs that reduced somatic growth or reproduction. All characteristics of each population exhibit density-independent dynamics, except first-year survival in the density-dependent models. The populations are closed systems, allowing no migration impact on population size. No stochastic factors are included. Ocean conditions, freshwater habitat, fishing pressure, and resource availability are assumed constant and densityindependent.

A prospective analysis of transition matrix $A$ as described by Caswell (2001) explored the population growth rate as a function of the vital rates. The population growth rate, $\lambda$, equals the dominant eigenvalue of $\boldsymbol{A}$ and was calculated using matrix analysis software (MATLAB version 6.5.0, The Math Works, Natick, MA, USA). The stable stage distribution, the proportional distribution of individuals among the stages when the population is at equilibrium, is given by $\mathbf{w}$, the right normalized eigenvector corresponding to the dominant eigenvalue $\lambda$. The influence of each matrix element $\left(a_{i j}\right)$ on $\lambda$ was assessed by calculating the sensitivity and elasticity values for $\mathrm{A}$. The sensitivity of matrix element $a_{i j}$ equals the rate of change in $\lambda$ with respect to $a_{i j}$, which is defined by $\delta \lambda / \delta a_{i j}$. Higher sensitivity values indicate greater influence on $\lambda$. The elasticity of matrix element $a_{i j}$ is defined as the proportional change in $\lambda$ relative to the proportional change in $a_{i j}$ and equals $\left(a_{i j} / \lambda\right)$ times the sensitivity of $a_{i j}$. One charac- 
teristic of elasticity analysis is that the elasticity values for a transition matrix sum to unity (de Kroon et al. 2000; Caswell 2001). The unity characteristic allows comparison of the influence of transition elements as well as the addition of a series of transitions to assess the roles of different life cycle stages or routes, a process called loop analysis. Loop analysis permits comparison of pathways, which are more likely to correspond directly to life history characteristics than individual elements (de Kroon et al. 2000; Caswell 2001). In a loop analysis, the life history graph is decomposed into the simple pathways of the life cycle, for example early and late reproduction in the life history graph (Figure 1). Transition elements with the highest elasticity values make the greatest contributions to changes in $\lambda$, and similarly the life cycle pathway or loop with the greatest sum of $e_{i j}$ values contributes the greatest of the possible pathways.

Each model projection was run for 20 iterations ( 1 iteration $=1$ year). The initial conditions for age-specific abundance equaled the baseline stable age distribution vector multiplied by $1 \times 10^{6}$, simulating a small stream population with approximately 300 age 5 individuals. Two exposure scenarios were modeled for each toxic impact. The first is a constant exposure over all iterations to represent constant inputs or sediment loads of compounds. The second represents a one generation exposure ( 5 years) occurring at model projection years 1 through 5 by simulating a spill and remediation of a contaminated site by either artificial or natural processes. Impacts were assessed by determining the response percentages: the abundance at the end of the 20-year toxic impact projection multiplied by 100 and divided by the abundance in the baseline projection. Response percentages were calculated for total abundance as well as age-specific abundance. For each constant impact projection, comparisons of the age distribution at time $t=20$ were made to the baseline output by calculating each age as a percent of the baseline distribution. This was done to easily show the trends in response across the different toxicity scenarios.

\section{Immune suppression models}

In defining the immune suppression models, it was assumed that chronic immune impacts result in reductions to survival only, that no compensation in energy balance occurs, and that stress is too low to significantly alter somatic growth rates or reproductive output. Research on Chinook salmon immunosuppression supports these assumptions (M. Arkoosh, DOC NOAA Fisheries, Newport Research Station, Newport, OR, USA, personal communication). Since chemical exposure is known to occur during estuary residence for outmigrating salmon, survival at age 1 is altered in all models by $10 \%$ of the baseline survival rate to simulate the effect of a low-level immune suppression. Chinook reared in contaminated estuaries have exhibited higher impacts due to immunosuppression (Arkoosh et al. 1998). Effects on later stages, due to delayed effects of estuarine exposure (Arkoosh et al. 1994, 1998, 2001; Milston et al. 2003) or due to effects of additional open ocean exposure (Krümmel et al. 2003), were modeled by reducing survival at each age by $10 \%$ in a cumulative manner for age 1 ; ages 1 and 2; ages 1, and 2, and 3; and so forth. Survival toxicity multipliers (STi) applied to the transition matrix represent this cumulative mortality impact. This includes 10\% reductions in each survival transition at age 1 (ST1); survival at ages 1 and 2 (ST1-2); survival at ages 1, 2, and 3 (ST1-3); and survival at ages $1,2,3$, and 4 (ST1-4).

\section{Reproductive models}

The laboratory and field studies investigating reproductive toxicity discussed in the introduction led to the question of whether chronic inhibition of reproductive function may lead to population-level effects. Toxicity impacts relating to reproductive inhibition were modeled. A 10\% reduction in various endpoints of reproductive output was chosen to be conservative relative to acceptable impacts (Stephan et al. 1985), since actual reductions would depend on the chemical or mixture of interest. Measuring this level of impact in the field would be difficult due to natural variability, but the level is similar to levels of significant response observed in laboratory tests (Healey and Heard 1984).

The reproductive inhibition models used in this study simulated toxic effects on reduction in fecundity, egg survival to emergence, the number of adults spawning, alterations in the time to reproductive maturity, and a combination of toxic effects reducing fecundity and adult survival. These reproductive characteristics were chosen because they are toxicity test measurement endpoints as well as important factors in the life history strategy of a population. The effects selected also reflect several types of exposure scenarios. Exposure before the adult spawning migration can produce alterations in fecundity and survival related to egg size and maternal transfer of toxic compounds. Contaminant exposure during the spawning migration can increase adult mortality and straying. Exposure at the spawning grounds can impact adult spawning behavior as well as hatch success. These impacts on reproductive output and number of spawners composed the first scenario simulated by a $10 \%$ reduction in the reproductive matrix elements $(\mathrm{R} 1-3$, first row of matrix) for reproductively mature ages 3,4 , and 5 , termed RT. Alterations in age to reproductive maturity are proposed effects of endocrine disrupters and constitute another set of reproductive impact scenarios as an increase or decrease in time to reproductive maturity for females (Adams et al. 1992; Kime 1999). Augmenting the proportions of individuals maturing at ages 3 and 4 by $10 \%$ of each age imposed a decrease in the age of maturity. Increases in the age of maturity were modeled by reducing the proportions of individuals for all reproductive age classes $(3,4$, and 5$)$ by $10 \%$. The parameter for proportion of reproductively mature females is integrated in the matrix reproductive values as well as survival terms S3 and S4.

\section{Growth inhibition models}

A quantitative relationship between growth and survival or reproductive effects has not been established in field studies of Chinook salmon. Therefore, it was assumed that some undetermined level of growth inhibition produces $10 \%$ reductions in reproduction and age-specific survival rates in various combinations discussed above. These combinations reflect several exposure scenarios. The primary scenario examines low-level exposures that produce reproductive toxicity at all ages in combination with cumulative mortality impacts. The models included $10 \%$ reductions in $\mathrm{RT}$ and survival during age 1 (ST1); RT and survival at ages 1 and 2 (ST1-2); RT and survival at ages 1, 2, and 3 (ST1-3); and RT and survival at ages $1,2,3$, and 4 (ST1-4). Ten percent impacts were chosen to match the other survival and reproduction models for comparison. Another exposure scenario encompasses effects that might occur from exposure at later ages or bioaccumulation over time to reach a threshold of effect. This scenario reduces reproduction at all ages and survival at age 3 and 4 (RT + ST3-4). 


\section{Density-dependent models}

Resource or habitat limitations normally influence the first-year survival rate in density-dependent fish populations (DeAngelis et al. 1980). Therefore, the density-dependent models were constructed using the Sl survival as the density-dependent factor. The growth rate at the population equilibrium was assumed to be the same as the growth rate in the density-independent models. The density-dependent factor for first-year survival (S1) was defined by a modified Beaverton-Holt recruitment model (Grant 1998), S1 = (1 $\mathrm{bm}) /\left(1-\left[b m\left\{1-\left(N 1_{t} / N 1_{\max }\right)\right\}\right]\right)$, with a baseline mortality $(\mathrm{bm})$ for age 1 of $\mathrm{bm}=0.9959$, age 1 abundance at time $t\left(\mathrm{Nl}_{t}\right)$, and a maximal capacity $\left(\mathrm{Nl}_{\max }\right)$ of age 1 individuals of 1,000,000. Competition for limited and heterogeneously distributed resources by subyearlings in the freshwater and estuary habitats guided the selection of the Beaverton-Holttype equation, which produces a lower first-year survival rate with increasing subyearling density. The initial condition for the abundance vector was the baseline equilibrium of $N\left(1.38 \times 10^{6} ; 4,105 ; 2,021 ; 1,077 ; 403\right)$. The toxicity models included the cumulative survival impacts ST1 to ST1-4, reproductive impacts, $\mathrm{RT}$, and combination impacts similar to growth effects RT + STl and RT + STl-4, all defined as in the above density-independent models.

\section{RESULTS}

\section{General model prospective analysis}

The baseline density-independent matrix produced a population growth rate $(\lambda)$ of 1.081 . Over a 20 -year projection, the total abundance increases by 339\%. The sensitivity analysis of the baseline matrix places the greatest influence on $\lambda$ with first-year survival (Table 1 ). The elasticity analysis of the baseline matrix revealed that changes to the first- and second-year survival rates will have the greatest per unit effect on $\lambda$ (Table 1). The loop elasticity analysis determining the relative importance of the three reproductive pathways (Figure 1C-E) confirms that age 4 and age 5 reproductive output contribute similarly to $\lambda$ under baseline conditions. The sensitivity analysis shows a lesser importance of age 5 reproduction, compared with age 4 reproduction, due to the larger numbers of individuals reproducing at age 4 (Table 2). The stable age distribution for the baseline model is age 1, $99.33 \%$; age 2, $0.3811 \%$; age $3,0.1736 \%$; age $4,0.0855 \%$; and age $5,0.0296 \%$.

\section{Immune suppression models}

The population growth rates and their respective differences show the change in $\lambda$ with each increment of the cumulative immune suppression scenarios (Table 3 ). The greatest calculated differences in $\lambda$ result from changes to S1 and S2. Loop elasticity analysis showed that as the immunosuppressive effects on survival accumulated from ST1 to ST4, the importance to $\lambda$ of any changes in fifth-year reproduction increases. Therefore, alteration of reproduction of age 5 individuals would have a greater impact on $\lambda$ when the younger ages are impacted, since fewer individuals are surviving to age 5 . This trend holds until the survival transition to age 5 is impacted. When ST3 is added, $\lambda$ drops by 0.021 , but when ST4 is added, reducing the abundance of age 5 spawners only, the corresponding reduction in $\lambda$ is half at 0.010 . The sensitivity and elasticity values shift only slightly for the various survival impact scenarios, with the impacted

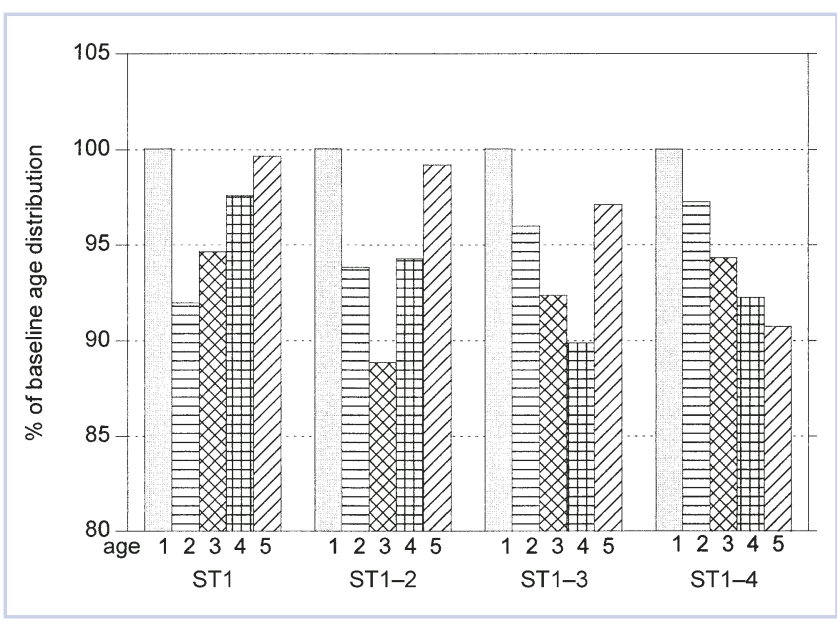

Figure 2. Chinook population stable age distribution relative to baseline age distribution resulting from cumulative constant $10 \%$ reduction in cumulative survival transitions (ST1, ST1-2, ST1-3, ST1-4). Bars represent ages 1-5 from left to right for each grouping. Calculation: (proportion age $i$ impacted/ proportion age $i$ baseline) $\times 100$. All abundance values used were from projection at 20 years.

transitions becoming more important than those not impacted (Table 2).

When the various impacts on survival are constant, the total population abundance ranges from 35 to $78 \%$ below the baseline projection values with no toxic impacts (Table 4). After the spill and cleanup exposure (T1-5), the population returns to baseline survival conditions. In this scenario the reduction of only S1 by $10 \%$ can lead to the population being 10\% below baseline within 20 years (Table 4 ). The age distributions show low, but consistent, shifts to slightly larger first-year groups, whereas the age groups immediately after the last impacted survival transition (age 3 for ST2) show the greatest decrease relative to the baseline age distribution (Figure 2).

\section{Reproductive models}

Under the first reproductive scenario (RT) in which reproductive contributions for ages 3,4 , and 5 are reduced by $10 \%, \lambda$ declined from 1.081 to 1.055 (Table 4 ). The increase in elasticity values R5 and L5 indicates an increased influence on $\lambda$ of age 5 through abundance and reproductive con-

Table 1. Matrix, sensitivity, and elasticity values for the baseline Chinook model. Si and Ri represent survival and reproductive transition elements from age $i$, respectively

\begin{tabular}{|l|c|l|c|}
\hline Transition & Matrix value & Sensitivity & Elasticity \\
\hline S1 & 0.004149 & 61.084 & 0.23437 \\
\hline S2 & 0.4925 & 0.5146 & 0.23437 \\
\hline S3 & 0.5328 & 0.4136 & 0.20381 \\
\hline S4 & 0.3744 & 0.2688 & 0.09307 \\
\hline R3 & 80.679 & 0.00041 & 0.03056 \\
\hline R4 & 593.42 & 0.000202 & 0.11074 \\
\hline R5 & 1440.4 & 0.0000699 & 0.09307 \\
\hline Loop 3 & & & 0.09167 \\
\hline Loop 4 & & & 0.44296 \\
\hline Loop 5 & & & 0.46535 \\
\hline
\end{tabular}


Table 2. Qualitative changes to sensitivity (S), elasticity (E), and loop elasticity (LE) values from baseline condition for each scenario. The second row indicates the matrix element (i.e., survival age $1=\mathrm{S} 1$, reproduction age $3=\mathrm{R} 3$, reproductive loop age 3 = L3, etc.), with + (increase), - (decrease), and 0 (no change, <0.001) from the baseline value. Rep = reproductive maturity

\begin{tabular}{|c|c|c|c|c|c|c|c|c|c|c|}
\hline Scenario & $\begin{array}{c}S \\
S 1\end{array}$ & $\mathbf{S 2}$ & S3 & S4 & R3 & R4 & R5 & & & \\
\hline ST1 & + & - & - & - & - & - & - & & & \\
\hline ST1-2 & + & + & - & - & - & - & - & & & \\
\hline ST1-3 & + & + & + & - & - & - & - & & & \\
\hline ST1-4 & + & + & + & + & - & - & - & & & \\
\hline RT & - & - & - & - & + & + & + & & & \\
\hline $\mathrm{RT}+\mathrm{ST} 1$ & + & - & - & - & - & + & + & & & \\
\hline RT + ST1-2 & + & + & - & - & - & + & + & & & \\
\hline RT + ST1-3 & + & + & + & - & - & - & + & & & \\
\hline RT + ST1-4 & 0 & 0 & 0 & 0 & 0 & 0 & 0 & & & \\
\hline Rep delay & - & - & - & - & + & + & + & & & \\
\hline \multirow[t]{2}{*}{ Rep early } & + & + & + & - & + & + & - & & & \\
\hline & $\begin{array}{c}\text { E } \\
\text { S1 }\end{array}$ & S2 & S3 & S4 & R3 & R4 & R5 & $\begin{array}{l}\text { LE } \\
\text { L3 }\end{array}$ & L4 & L5 \\
\hline ST1 & - & - & + & - & - & - & + & - & - & + \\
\hline ST1-2 & - & - & + & + & - & - & + & - & - & + \\
\hline ST1-3 & - & - & - & + & - & - & + & - & - & + \\
\hline ST1-4 & + & + & - & - & + & + & - & + & + & - \\
\hline RT & - & - & + & + & - & - & + & - & - & + \\
\hline RT + ST1 & - & - & + & + & - & - & + & - & - & + \\
\hline RT + ST1-2 & - & - & + & + & - & - & + & - & - & + \\
\hline RT + ST1-3 & - & - & - & + & - & - & + & - & - & + \\
\hline RT + ST1-4 & 0 & 0 & 0 & 0 & 0 & 0 & 0 & 0 & 0 & 0 \\
\hline Rep delay & - & - & + & + & - & - & + & - & - & + \\
\hline Rep early & + & + & + & - & + & + & - & + & + & - \\
\hline
\end{tabular}

Table 3. Population growth rates of baseline and immune suppression scenarios. STi represents a $10 \%$ reduction in survival of age $i$ individuals to age $i+1$. RT represents a 10\% reduction in reproductive output for all mature ages (3-5). The third column shows the change in $\lambda$ for each additional insult. The fourth column shows the abundance difference of age 5 individuals from initial conditions to projection time $t=20$

\begin{tabular}{|c|c|c|c|}
\hline Survival scenario & $\lambda$ & $\begin{array}{c}\text { Difference from } \\
\text { previous } \lambda\end{array}$ & $\begin{array}{c}\% \text { Change from } \\
t=1 \text { to } t=20\end{array}$ \\
\hline Baseline Chinook & 1.081 & & +339 \\
\hline ST1 & 1.055 & -0.026 & +185 \\
\hline ST1-2 & 1.029 & -0.026 & +81 \\
\hline ST1-3 & 1.008 & -0.021 & +17 \\
\hline ST1-4 & 0.998 & -0.010 & -10 \\
\hline \multicolumn{4}{|c|}{ Combination scenarios } \\
\hline Baseline Chinook & 1.081 & & +339 \\
\hline RT & 1.055 & -0.026 & +192 \\
\hline RT + ST1 & 1.029 & -0.026 & +95 \\
\hline RT + ST1-2 & 1.004 & -0.025 & +24 \\
\hline RT + ST1-3 & 0.983 & -0.021 & -18 \\
\hline RT + ST1-4 & 0.973 & -0.010 & -35 \\
\hline
\end{tabular}




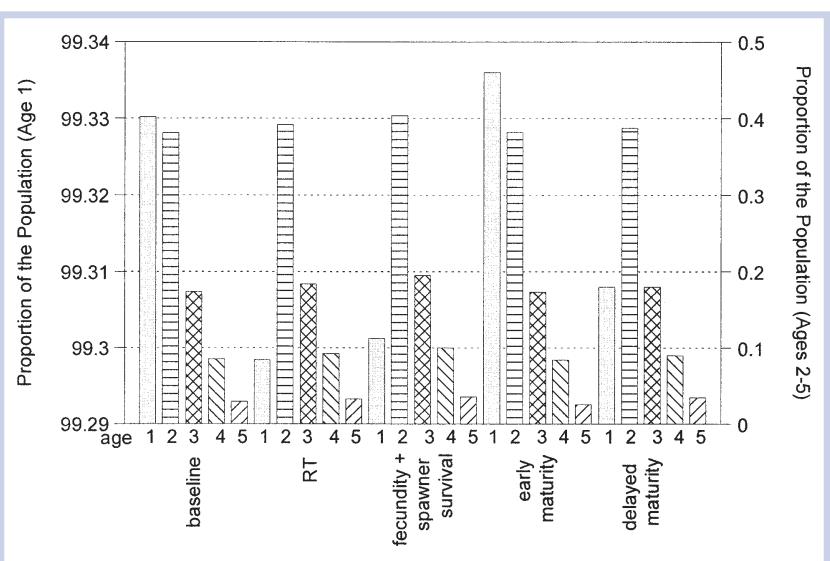

Figure 3. Chinook population stable age distribution as a result of a constant $10 \%$ reduction in reproductive parameters over a 20 -year projection.

tributions. The age distribution of this scenario shifted to a gradually higher proportion of age 2, 3, 4, and 5 individuals relative to the baseline (Figures 3 and 4 ). At the end of a 20year constant exposure scenario for RT, the abundance values for ages 1 and 5 were $60 \%$ and $66 \%$ of the baseline run, respectively (data not shown). The differences between age groups reflect the change in the age distribution toward older individuals (Figures 3 and 4). Although constant exposure produced a total abundance of $60 \%$ of baseline at 20 years, after exposure from years 1 through 5 , the 20 -year projected population was approximately $86 \%$ of baseline.

Toxic exposure affecting adults returning to spawn was depicted as a $10 \%$ reduction in both fecundity and adult spawning migration survival. In RT, a value of 0.9 was used as a multiplier for R3, R4, and R5 and alteration of fecundity and spawning migration survival used a multiplier of 0.81 $\left(0.9^{2}\right)$. The responses were more extreme than those of fecundity and adult migration survival alone, but had the same age distribution, sensitivity, and elasticity values (Figures 3 and 4). The population growth rate was reduced to 1.029 , a change from RT of -0.026 . Similar trends were observed since the same transition elements were altered in a consistent manner by using the same multiplier for all of the values. After the 20-year constant exposure projection, the abundance values ranged from 36\% of baseline for age 1 to $43 \%$ of baseline for age 5 (data not shown).

Alterations of the age of female reproductive maturity compose the second set of scenarios. When the age at reproduction is delayed by $10 \%$, the number of reproductively mature individuals is multiplied by 0.9 for ages 3, 4, and 5 . Fewer fish reproducing at ages 3 and 4 results in a larger number surviving to ages 4 and 5 , leading to greater reproductive contributions for those year classes. An additional age 6 was not added for fish that do not mature at age 5 since ocean-type Chinook rarely reproduce after age 5 (Groot and Margolis 1991). The population growth rate dropped to 1.069 for this scenario compared with the baseline value of 1.081 . The sensitivity values for survival decreased from the baseline and those for reproductionincreased (Table 2). The elasticity values reveal a large increase in influence of the age 5 reproduction and survival and proportional drop in age 3 and 4 contributions to changes in the growth rate due to the increase in older individuals (Table 2). The reproductive contribution of age 4 remains important, but lesser than in the baseline scenario. The age distribution has shifted to a larger proportion of age 5 abundance as is depicted

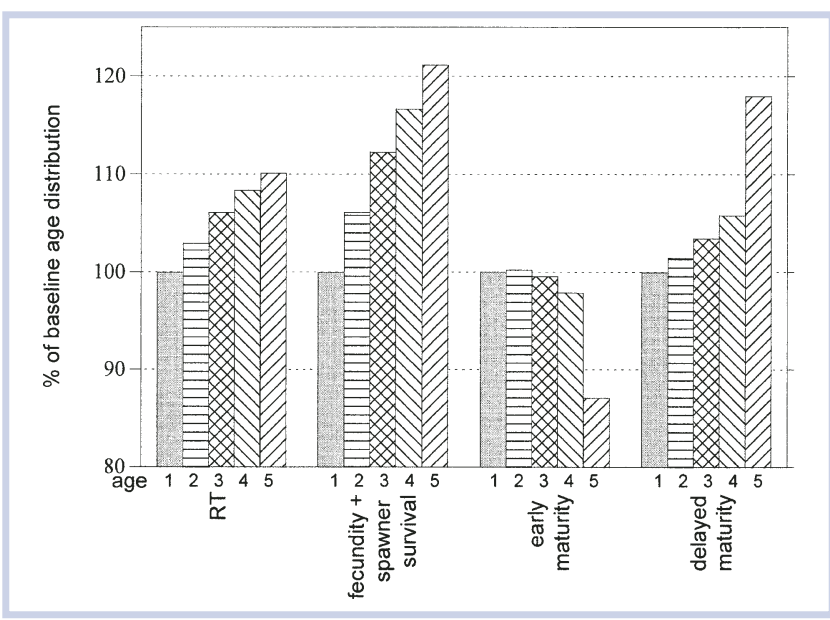

Figure 4. Chinook population stable age distributions relative to the baseline age distribution as a result of a $10 \%$ reduction in each reproductive parameter. Calculation: (proportion age $i$ impacted/proportion age $i$ baseline) $\times 100$. All abundance values used were from projection at 20 years.

in Figure 4. After the 20-year constant impact projection, age 1 and age 5 abundance values were 77 and $91 \%$ of the baseline run, respectively. After 20 years, the total abundance was approximately $77 \%$ of baseline. When the effects of delayed maturity were limited to the first 5 years of the projection, the final total abundance was $96 \%$ of baseline (Table 4 ).

When the age at reproduction is decreased, the proportion of reproductively mature individuals for ages 3 and 4 is multiplied by 1.10 such that $10 \%$ more females are reproductively mature at each age. Although this increases reproduction at ages 3 and 4, the subsequent mortality decreases the number of individuals surviving to ages 4 and 5. The population growth rate increases slightly from 1.081 to 1.082 , resulting in a total abundance that was $102 \%$ of baseline after 20 years (Table 4). The sensitivity and elasticity analyses highlight a shift to increased importance of changes in early survival (S1 and S2) and age 3 and 4 reproduction (Table 2). This corresponds with a slight shift in the age distribution to fewer age 5 individuals, with only $89 \%$ of baseline after 20 years (Figure 4).

\section{Growth inhibition models}

The first set of growth inhibition models evaluated consistent reductions in reproductive and survival transition elements, combining the RT and cumulative mortality scenarios. The population growth rates and differences for $10 \%$ reductions in reproductive and survival rates reflect the additive effects of combining the RT and STi scenarios (Table 3). As in the immune suppression models, reduction in survival rates to ages 4 and 5 produced lesser net differences. The same pattern and net changes were produced with the addition of each insult to the survival transition elements. After the addition of ST3, the response percentages for the constant exposure range from 14 to $18 \%$ (Table 4 ). The addition of each survival impact reduces the relative abundance of the following stage until all transitions are impacted and the distributions are similar to baseline in RT $+\mathrm{STl}-4$ (Figure 5). Similar to the immune suppression scenarios, the sensitivity and elasticity analyses show an increased importance and proportional contribution of the age 5 reproductive loop when the earlier survival transitions (ST1-3) are impacted (Table 2). This holds until the survival transition from age 4 to age 5 is impacted, since the combined impact is calculated by multiplying all nonzero elements in the transition 
Table 4. Response percentages for toxicity scenarios relative to baseline. STi represents a $10 \%$ reduction in survival of age $i$ individuals to age $i+1$. Exposure regimes include constant (all 20 years of projection) and T1-5 (projection years $1-5)$. STi represents a 10\% reduction in survival of age $i$ individuals to age $i+1$. RT and reduction of fecundity (fec) and adult survival represent $10 \%$ reductions in respective aspects of reproductive output for all mature ages. Reproductive delay and early maturity alter the proportion of reproductively mature females in ages 3 and 4 by $10 \%$. The last column shows the effect of a $25 \%$ impact on select scenarios

\begin{tabular}{|c|c|c|c|}
\hline Scenario & Exposure & $\%$ Baseline $10 \%$ impact & $\%$ Baseline $25 \%$ impact \\
\hline \multirow[t]{2}{*}{ ST1 } & Constant & 65 & 31 \\
\hline & $\mathrm{T} 1-5$ & 90 & 76 \\
\hline \multirow[t]{2}{*}{ ST1-2 } & Constant & 41 & \\
\hline & $\mathrm{T} 1-5$ & 82 & \\
\hline \multirow[t]{2}{*}{ ST1-3 } & Constant & 28 & \\
\hline & $\mathrm{T} 1-5$ & 75 & \\
\hline \multirow[t]{2}{*}{ ST1-4 } & Constant & 23 & \\
\hline & $\mathrm{T} 1-5$ & 72 & \\
\hline \multirow[t]{2}{*}{ RT } & Constant & 60 & 27 \\
\hline & $\mathrm{T} 1-5$ & 86 & 71 \\
\hline \multirow{2}{*}{$\begin{array}{l}\text { Delay } \\
\text { reproductive } \\
\text { Maturity }\end{array}$} & Constant & 77 & \\
\hline & $\mathrm{T} 1-5$ & 96 & \\
\hline \multirow{2}{*}{$\begin{array}{l}\text { Early } \\
\text { reproductive } \\
\text { Maturity }\end{array}$} & Constant & 102 & \\
\hline & $\mathrm{T} 1-5$ & 100 & \\
\hline \multirow{2}{*}{$\begin{array}{l}\text { Reduce fec } \\
\text { and } \\
\text { Adult survival }\end{array}$} & Constant & 36 & \\
\hline & $\mathrm{T} 1-5$ & 76 & \\
\hline \multirow[t]{2}{*}{$\mathrm{RT}+\mathrm{ST} 1$} & Constant & 40 & 8 \\
\hline & T1-5 & 80 & 54 \\
\hline \multirow[t]{2}{*}{ RT + ST1-2 } & Constant & 26 & \\
\hline & T1-5 & 70 & \\
\hline \multirow[t]{2}{*}{ RT + ST1-3 } & Constant & 18 & \\
\hline & $\mathrm{T} 1-5$ & 64 & \\
\hline \multirow[t]{2}{*}{ RT + ST1-4 } & Constant & 14 & 0.5 \\
\hline & $\mathrm{T} 1-5$ & 60 & 26 \\
\hline \multirow[t]{2}{*}{ RT + ST3-4 } & Constant & 35 & \\
\hline & $\mathrm{T} 1-5$ & 80 & \\
\hline
\end{tabular}

matrix A by a constant (0.9). Multiplying the matrix by a scalar results in no change in elasticity or sensitivity from the baseline (data not shown)

The reproductive and adult survival impact scenario (RT + ST3 + ST4) produces a population growth rate of 1.026 , higher than when the earlier transitions are altered, such as $\mathrm{RT}+\mathrm{ST} 1-2$ (Table 3). This can be attributed to the increasing relative abundance of ages 3 and 4 (Figure 5) and the high reproductive contribution of age 4 .

\section{Density-dependent models}

Under constant impact conditions the density-dependent model output shifts to a new, lower equilibrium abundance (Figure 6). When STl is the only impacted survival transition, there is no alteration of age distribution from the baseline due to survival rate compensation at this stage (Figure
6). In all other cases, a new equilibrium and a new age distribution result for each type of insult. Density-dependent compensation in the STl scenario produces a lower equilibrium but no change in the age distribution. Additional insults to survival in the cumulative models produce a further decrease in each stage after the insult as well as a decrease in reproduction and age 1 individuals (Figure 6). Densitydependent compensation yields a relatively constant proportion of age 2 individuals. The RT scenario has no impact on the age distribution for ages 2 to 5 because of the survival compensation afforded by the density dependence of the reduced abundance of age 1 individuals.

When the exposure for all toxicity scenarios was limited to one generation ( $\mathrm{T} 1-5)$, the abundance values initially dropped to the new equilibria, equivalent to those in the constant impact models. After the exposure ended at year 


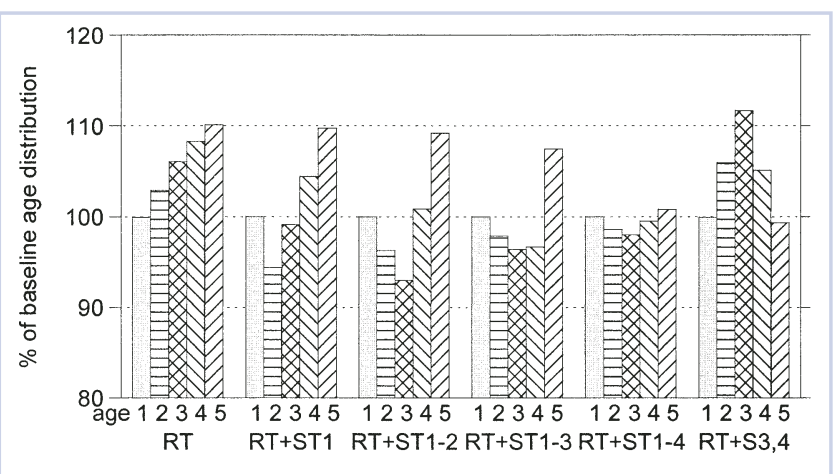

Figure 5. Chinook population stable age distributions relative to the baseline age distribution resulting from $10 \%$ reductions in survival and reproduction due to growth inhibition. Calculation: (proportion age $i$ impacted/proportion age $i$ baseline) $\times 100$. All abundance values used were from projection at 20 years.

5 , the abundance returned to the baseline values within 9 years, or less than two generations.

\section{DISCUSSION}

Sublethal effects from toxic exposures have been implicated as important factors in population decline. Sibly et al. (2000) concluded that both the sublethal and lethal impacts of dieldrin contributed to the rapid decline of sparrowhawks in parts of Great Britain. Declines in estuarine and coastal fish populations were noted by Matthiessen and Law (2002) while reviewing impacts of estuary and nearshore contamination. Kroglund and Finstad (2003) observed lower marine survival in Atlantic salmon (Salmo salar) after presmolt exposure to low concentrations of aluminum in acidic freshwater. The purpose of this modeling study was to determine how various types of sublethal toxic impacts may be expressed at the population level based upon the life history strategy of the species of concern, Chinook salmon. Low-level effects were shown to produce consequential reductions in abundance for most of the model scenarios. The overall goal was to gauge potential impacts due to contaminant exposure and to compare different biological responses. Application of the approach discussed in this paper to regulatory or research efforts must combine the analysis presented here with specific knowledge of the exposure and life history characteristics of the species of interest.

Due to the anadromous and semelparous life history of Chinook salmon, impacts of somatic growth reductions may differ from those observed in other species. Reductions in the somatic growth rate of salmon fry and smolts are believed to result in increased size-dependent mortality (Healey 1982; West and Larkin 1987), primarily because they must reach a critical or threshold size to successfully transition from freshwater to seawater (smoltification) (Beamish and Mahnken 2001). A second threshold size has been hypothesized for survival over the first winter in the open ocean (Beamish and Mahnken 2001). Coded wire tag studies have shown that fish that survive to their first winter but are smaller than the threshold size to meet minimum metabolic requirements do not survive the winter (Heintz et al. 2000; Beamish and Mahnken 2001). Observations have shown a normal distribution of sizes entering the threshold life stage and a loss of individuals from the lower tail of the distribution below the threshold size, resulting in a larger mean size for survivors (Beamish and Mahnken 2001). These studies suggest that the primary influence of reductions in somatic growth

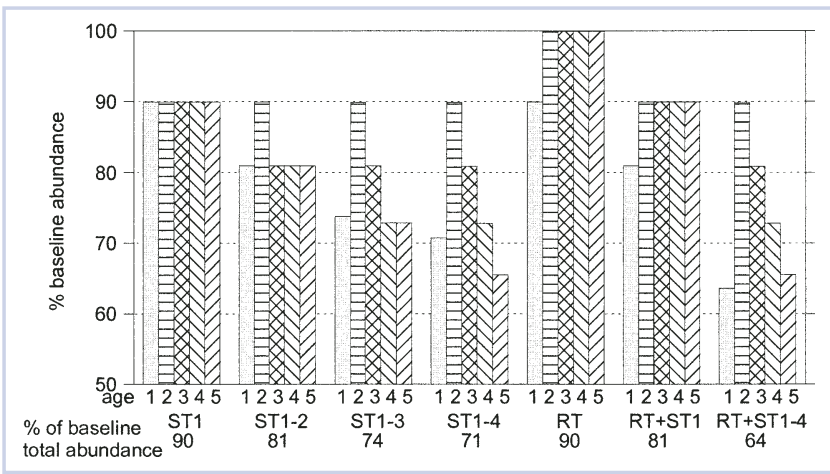

Figure 6. The new equilibrium values for each age group from the constant toxic impact scenarios represented as the percent of baseline equilibrium abundance for the density-dependent models. Values along the bottom indicate the percent of baseline equilibrium abundance for total abundance at $t=20$.

caused by toxic insult will result in increased smolting and first-year overwintering mortality.

The STl scenario from our study may best characterize the above factors related to reductions in somatic growth in Chinook salmon. This encompasses the multiple size thresholds that must be surpassed for survival during the first year of life. Heintz et al. (2000) observed that fish surviving juvenile growth inhibition exhibit an average length upon returning to their natal stream, but not necessarily an average weight, which may translate into lower reproductive success. Fish with a lower condition factor (i.e., lower weight/length ratio) have increased oocyte atresia and decreased fecundity (Trippel et al. 1997; Laine and Rajasilta 1999; Kurita et al. 2003). In addition, a direct relationship between reduced fecundity and female body length has been observed over time in Chinook and coho salmon at the University of Washington hatchery (Quinn et al. 2000). The RT + STl scenario may best fit cases when somatic growth inhibition also leads to reductions in reproductive output due to lowered condition or length.

The concept of delayed effects, impacts that extend beyond the life stage in which the exposure occurs, as depicted in our cumulative models, is not new and has been observed in salmon. Studies in our laboratory indicate that when juvenile Chinook salmon are exposed to PAHs, they experience both somatic growth reduction as well as increased mortality when subjected to overwinter starvation. In addition, Heintz et al. (2000) observed a significant reduction in survival to maturity in pink salmon (Oncorhynchus gorbuscha) exposed to crude oil during embryonic development in an experiment that was initiated with the release of healthy-looking smolts. These studies may reflect only the growth effects on mortality at age 1 , but it is not certain.

There is a growing body of evidence demonstrating that sublethal effects on individual organisms are occurring after exposure to environmentally relevant concentrations. The examples that follow represent a few of the studies that have shown low-level effects in salmonids. Field studies by Arkoosh et al. (1998, 2001) documented significant and longterm immunosuppression in Chinook salmon with concentrations of total PAHs in stomach contents as low as $8 \mathrm{ppm}$ wet weight, far lower than stomach contents of fish collected in urban estuaries that ranged up to $365 \mathrm{ppm}$ wet weight (Varanasi et al. 1993). Other studies have simulated environmental conditions in a laboratory setting by exposing eggs and larvae to extracts of contaminated sediments. Heintz et 
al. (2000) used this method to show decreased growth and marine survival in pink salmon exposed $5.4 \mathrm{ppb}$ to PAHs during development, simulating exposure to weathered crude oil. In another study, 4-d-old surf smelt exposed for $96 \mathrm{~h}$ to sediment extracts of 11 and $29 \mathrm{ppm}$ total PAHs exhibited increased mortality, decreased length, and increased abnormal larvae (Misitano et al. 1994). Rice et al. (2000) found a severe growth reduction in English sole (P. vetulus) fed polychaete worms exposed to a $0.1 \%$ dilution of sediment from Eagle Harbor, Washington, USA. The total PAH tissue concentration in worms of $11.3 \mathrm{ppm}$ (wet weight) fed at $6 \%$ body weight/d was high enough to reduce the growth rate in fish by 10 - to 25 -fold. These studies represent a few examples of sublethal effects in organisms exposed to environmentally relevant concentrations of contaminants and support our choice of model scenarios that examine such low-level responses.

A toxic impact resulting in a $10 \%$ reduction in survival rates is often considered acceptable in regulatory situations and is usually within the limits of statistical nonsignificance for toxicity tests (Suter 1993). At this impact level, the results of our study indicate a substantial reduction in the growth rate of the population (Table 4 ). When the various effects are constant, the total population abundance ranges from 35 to $78 \%$ below the values projected with no toxic impacts (Table 4). The one-generation exposure during projection years 1 to 5 (T1-5) simulates the effects of a spill and cleanup scenario. After the exposure, the population exhibits baseline survival and reproduction conditions. In the density-independent models, a recovery to match baseline abundance is not possible since the impacted population abundance will experience a time lag related to the time of exposure and the resulting age distribution. This can result in long-term impacts to abundance after chronic toxicity exposures. The reduction of first-year survival by $10 \%$ for 5 years can lead to the population being more than $10 \%$ below its potential baseline abundance 15 years after cessation of exposure. Snell and Serra (2000) modeled the impacts of changes in the instantaneous rate of population growth, $r$, on rotifer populations at lower impact levels than were tested in this study. They found that population viability was significantly reduced and extinction became more likely at purportedly safe toxicant concentrations (e.g., no observed effect concentrations [NOEC]), although only very small changes in $r$ were observed.

It is important to keep in mind that these results reflect the impact from a single stressor. When multiple stressors are considered, the impact to population dynamics will be that much more complex and may lead to larger population perturbations. Continued immune suppression after the initial exposure during the estuary residence could provide those additional effects, even if only a few cohorts are exposed (Table 4).

As described above, even in the laboratory measuring a $10 \%$ reduction in an endpoint as a significant difference from control can be difficult, requiring large sample sizes and precise endpoints. Low-level effect concentrations, such as an EC10, are most often calculated from a dose-response curve and not directly measured. In the field, measuring population- or community-level changes in metrics often carries a variance of $\pm 20 \%$ due to natural variability and measurement limitations. To demonstrate how the models respond to measurable impacts, additional model runs were conducted us- ing a $25 \%$ reduction in each of the survival and reproductive parameters. The constant impact models for STl, RT, and $\mathrm{RT}+\mathrm{ST} 1-4$ resulted in response percentages of 31,27 , and $0.5 \%$ of baseline, respectively. The spill and cleanup scenario (T1-5) for STl, RT, and RT + STl-4 resulted in response percentages of 76,71 , and $26 \%$, respectively (Table 4). Output from these models followed the same trends in sensitivity, elasticity, and age distributions as the $10 \%$ models, but with a greater magnitude of change. This demonstrates that regardless of the magnitude of the effect, the impact, such as decreased survival and reproduction related to somatic growth reduction, will lead to a similar pattern of response, particularly with respect to population age structure. The response patterns reflect the impacted life history stages as seen in the shifts in the stable age distributions (Figures 2, 4 , and 5). Although accurate means of measuring this level of age distribution change for populations in a variable environment are unavailable, management and regulatory decisions need to recognize these potential population-level responses.

First-year survival (S1) (Table 1) has been identified by these models as the factor that has the greatest impact on the Chinook salmon life history strategy. The importance of S1 to the population growth rate agrees with other models of Chinook salmon (Ratner et al. 1997; Kareiva et al. 2000). Unfortunately, this vital life stage corresponds with utilization of estuarine and nearshore habitats, which often contain the highest concentrations of contaminants and maximal exposure. Other important effects for Chinook salmon appear to be impacts that decrease the number of age 4 and 5 spawning females. Growth effects that occur prior to the size thresholds for smoltification and the first winter at sea will have large impacts on population growth rate. Any impacts to the first-year survival in density-independent populations will have greater relative effects than impacts on subsequent survival or on reproductive endpoints, such as fecundity, because it is common to all of the reproductive loops. This is not to say that the reproductive endpoints should be disregarded, particularly if density dependence is suspected, but emphasis should be placed upon first-year survival (e.g., S1). For example, immune suppression reduced total population abundance and altered the age distribution even when only the juveniles in smolt stage were exposed during the estuary residence (STl in Table 4). Low-level episodic exposures may not produce a large change in abundance, but a continuous low-level exposure can produce dramatic effects (Table 4). Other measurement endpoints that should be considered and modeled are behavioral responses. For example, a study by Scholz et al. (2000) has shown that Chinook salmon exposed to environmentally relevant concentrations of diazinon exhibited behavioral changes that reduced predator avoidance and increased straying during migration.

Debate remains about whether Pacific salmon populations experience density-dependent population dynamics and how it should be incorporated into population models (Peterman 1980; Grant 1998; Grant and Benton 2000; Kareiva et al. 2000; Sabo et al. 2004; Todd et al. 2004). Density dependence has been observed in some populations during the freshwater, estuary, and early marine survival stages, but not all populations examined have shown these dynamics (Peterman 1980). It has been suggested that salmon listed under the ESA have too low an abundance to trigger most density-dependent dynamics (Kareiva et al. 2000). Previ- 
ous simulation studies have suggested that toxic impacts will have a lesser effect on density-dependent populations than on density-independent populations (Grant 1998; Forbes et al. 2001). Grant and Benton (2000) determined that even in stochastic environments an elasticity analysis of $\lambda$ for a density-independent population provides an accurate approximation for the density-dependent population, provided the density dependence is limited to certain life stages, not autocorrolated with stochasticity and not involving bifurcation to nonlinear dynamics. Only the freshwater and estuary stages of Chinook are hypothesized to experience density dependence, and nonlinear dynamics are not suspected. Therefore, in our study we applied generalizations identified for density-independent models to the density-dependent models (Kareiva et al. 2000; Caswell 2001). Because density-dependent compensation is modeled for year class 1 (e.g., S1), the most important transition according to our elasticity and sensitivity analysis, the focus for effects shifts to the other factors that directly alter the number of spawning females (e.g., survival transitions to later ages S2, S3, and S4), which were important phases for the density-independent models. A possible caveat to this is the possible timing of the toxic effects and density-dependent compensation. Since the modeled freshwater and estuary exposures produce delayed effects, toxicants may not impact Sl until the fish has moved away from the nearshore, after the potential for density-dependent compensation has passed. If this were the case, density dependence during S1 would not likely compensate for impacts until the exposed cohorts reproduced. In this case the STl scenario would act more like the STl-2 scenario and decrease the abundance of ages 1, 3, 4, and 5 (Figure 6). Due to the uncertainty of the timing and extent of the density dependence in Chinook populations, potential impacts should be assessed without relying on the possibility of density-dependent compensation until more data become available.

\section{APPLICATION}

The findings in this study emphasize the importance of integrating demographic traits along with specific stressor attributes into risk assessments. When modeling is done for specific prospective risk assessments, they should incorporate not only the life history characteristics of the focal species, but also the aspects of the life history that may be impacted by the stressor. This study demonstrates that $\mathrm{EClO}$ values for various endpoints such as immune function, somatic growth, or fecundity should not be treated as equivalent impacts. The demographic traits impacted vary according to the stressor, and the relative importance of those traits depends on the life history strategy of the focal species. For instance, from a demographic point of view, impacts to first-year survival of Chinook salmon, in the absence of density dependence, will produce the greatest impacts to abundance and age structure. As an example, growth inhibition affecting both size-dependent survival and reproductive contributions will likely produce a greater change in the population abundance and population growth rate than commensurate impacts on immune function or reproduction individually. Assessment of the age structure reveals distinctions between types of impact based on the demographic traits involved. Although wild populations will not reach a stable age distribution, they will tend toward these proportions and may affect changes in evolution of the life history traits. Increasing mortality of older fish, through toxicity or harvesting, selects for individuals that mature at a younger age and has been observed in coho and Chinook (Roni and Quinn 1995; Quinn et al. 2000). Younger fish, being smaller, often have a lower fecundity and hatch rate (Bagenal 1969; Healey and Heard 1984; Wootton 1992; Roni and Quinn 1995). Possible changes in individual productivity are not always obvious without long-term monitoring due to the sheer abundance of younger spawners. For these reasons, we recommend incorporation of both specific demographic and stressor attributes into the models for use in the decision-making processes.

The relative rankings of the various endpoint impacts will likely apply to other salmonids, but with extreme caution, as the models discussed here are specific to ocean-type Chinook. Further study on other life history types is ongoing to investigate how broad these findings may apply. Stressor responses in conjunction with life in a stochastic environment also need to be considered. For example, the effect of smolt size on marine survival becomes particularly important during unfavorable marine conditions, but less so during favorable conditions (Holtby et al. 1990).

It was not our intent in this study to determine the impacts of chemical contaminants relative to other impacts wild Chinook salmon may experience. Natural variability, habitat degradation, or harvest practices would likely mask the levels of impact modeled here. However, that does not remove the consequence of the toxicant impacts on the populations. This study provides insight toward identifying potential sources of impact that result from human activity to target for remediation. Reclaiming extensive areas of habitat or improving ocean productivity may address larger impacts to salmon recovery, but these options are often not feasible. Reducing exposures of juvenile salmon to anthropogenic contaminants in freshwater, estuary, or nearshore marine habitats may be more practical while substantially contributing to population persistence.

\section{CONCLUSION}

The objective of this study was to determine how various sublethal toxic impacts and their measured endpoints may be expressed at the population level based on the life history characteristics of the population of concern. The main effects on Chinook salmon modeled in this study were expressed in the output as abundance reductions and shifts in the stable age distribution. These effects would not likely be observed in normal abundance surveys due to natural variability. Without specific baseline data on abundance and age distributions, observing these low-level impacts would require intensive long-term monitoring. Although identifying these effects in natural systems may be difficult, this study serves to identify potential impacts before they can be measured, whereas appropriate precautionary actions may be taken to reduce the repercussions (Santillo et al. 1998). Combinations of stressors found in the natural environment may also complicate interpretation of monitoring data. The results of this study support the hypothesis that first-year survival has the greatest influence on altering the population growth rate for ocean-type Chinook salmon. For this reason, conservation and regulatory efforts should focus on the impacts during first-year stream and estuary residence as well as migration to the ocean. Findings from this study also suggest that focus needs to be on studies that examine delayed effects from toxic exposure and that link body size and survival to reproductive output. 
Acknowledgement-NOAA Fisheries funding was provided through a National Research Council postdoctoral fellowship. The authors would like to thank Sue Ratner, Correigh Greene, and two anonymous reviewers for their constructive comments on the manuscript.

\section{REFERENCES}

Adams SM, Crumby WD, Greenley MS Jr., Shugart LR. 1992. Responses of fish populations and communities to pulp mill effluents: A holistic assessment. Ecotoxicol Environ Saf 24:347-360.

Ankley GT, Tillitt DE, Giesy JP, Jones PD, Verbrugge DA. 1991. Bioassay-derived $2,3,7,8$-tetrachlorodibenzo- $p$-dioxin equivalents in PCB-containing extracts from the flesh and eggs of Lake Michigan Chinook salmon (Oncorhynchus tshawytscha) and possible implications for reproduction. Can J Fish Aquat Sci 48:1685-1690.

Arkoosh MR, Casillas E, Huffman P, Clemons E, Evered J, Stein JE, Varanasi U. 1998. Increased susceptibility of juvenile Chinook salmon from a contaminated estuary to Vibrio anguillarum. Trans Am Fish Soc 127:360-374.

Arkoosh MR, Clemons E, Huffman P, Kagley AN, Casillas E, Adams N, Sanborn HR, Collier TK, Stein JE. 2001. Increased susceptibility of juvenile Chinook salmon to vibriosis after exposure to chlorinated and aromatic compounds found in contaminated urban estuaries. J Aquat Anim Health 13:257-268.

Arkoosh MR, Clemons E, Myers MS, Casillas E. 1994. Suppression of B-cell mediated immunity in juvenile Chinook salmon (Oncorhynchus tshawytscha) after exposure to either a polycyclic aromatic hydrocarbon or to polychlorinated biphenyls. Immunopharmacol Immunotoxicol 16:293-314.

Bagenal TB. 1969. Relationship between egg size and fry survival in brown trout Salmo trutta L. J Fish Bio 1:349-353.

Beamish RJ, Mahnken C. 2001. A critical size and period hypothesis to explain natural regulation of salmon abundance and the linkage to climate and climate change. Prog Oceanog 49:423-437.

Caswell H. 2001. Matrix population models: Construction, analysis, and interpretation. Sundarland (MA), USA: Sinauer.

Chen TT, Reid PC, Van Beneden R, Sonstegard RA. 1986. Effect of Aroclor 1254 and Mirex on estradiol-induced vitellogenin production in juvenile rainbow trout (Salmo gairdneri). Can J Fish Aquat Sci 43:169-173.

de Kroon H, van Groenendael J, Ehrlen J. 2000. Elasticities: A review of methods and model limitations. Ecology 81:607-618.

DeAngelis DL, Svoboda $\sqcup$, Christensen SW, Vaughan DS. 1980. Stability and return times of Leslie matrices with density-dependent survival: applications to fish populations. Ecol Model 8:149-163.

Fast DE, Hubble JD, Kohn MS. 1988. Yakima River Spring Chinook enhancement study, Annual Report FY 1988. Toppenish (WA), USA: Yakama Indian Nation. U.S. Dept. of Energy, Bonneville Power Administration Division of Fish and Wildlife. Project 82-16.

Finlayson BJ, Verrue KM. 1985. Toxicities of butoxyethanol ester and propylene glycol butyl ether ester formulations of 2,4-dichlorophnoxy acetic acid (2,4-D) to juvenile salmonids. Arch Environ Contam Toxicol 14:153-160.

Forbes VE, Sibly RM, Calow P. 2001. Toxicant impacts on density-limited populations: A critical review of theory, practice, and results. Ecol App/ 11:1249-1257.

Glubokov Al. 1990. Growth of three species of fish during early ontogeny under normal and toxic conditions. Vopr Ikhtiol 30:137-143.

Grant A. 1998. Population consequences of chronic toxicity: Incorporating density dependence into the analysis of life table response experiments. Ecol Model 105:325-335.

Grant A, Benton TG. 2000. Elasticity analysis for density-dependent populations in stochastic environments. Ecology 81:680-693.

Groot C, Margolis L. 1991. Pacific salmon life histories. Vancouver (BC), Canada: Vancouver University British Columbia Press.

Hansen JA, Lipton J, Welsh PG, Morris J, Cacela D, Suedkamp MJ. 2002. Relationship between exposure duration, tissue residues, growth, and mortality in rainbow trout (Oncorhynchus mykiss) juveniles sub-chronically exposed to copper. Aquat Toxicol 58:175-188.

Healey MC. 1982. Timing and relative intensity of size-selective mortality of juvenile chum salmon (Oncorhynchus keta) during early sea life. Can J Fish Aquat Sci 39:952-957.

Healey MC, Heard WR. 1984. Inter- and intra-population variation in the fecun- dity of Chinook salmon (Oncoryhchus tshawytscha) and its relevance to life history theory. Can J Fish Aquat Sci 41:476-483.

Heintz RA, Rice SD, Wertheimer AC, Bradshaw RF, Thrower FP, Joyce JE, Short JW. 2000. Delayed effects on growth and marine survival of pink salmon Oncorhynchus gorbuscha after exposure to crude oil during embryonic development. Mar Ecol Prog Series 208:205-216.

Holtby LB, Andersen BC, Kadowak RK. 1990. Importance of smolt size and early ocean growth to interannual variability in marine survival of coho salmon (Oncorhynchus kisutch). Can J Fish Aquat Sci 47:2181-2194.

Johnson LL, Casillas E, Sol SY, Collier TK, Stein JE, Varanasi U. 1993. Contaminant effects on reproductive success in selected benthic fish. Mar Environ Res 35:165-170.

Johnson LL, Misitano D, Sol SY, Nelson GM, French B, Ylitalo GM, Hom T. 1998. Contaminant effects on ovarian development and spawning success in rock sole from Puget Sound, Washington. Trans Am Fish Soc 127:375-392.

Johnson LL, Sol SY, Lomax DP, Nelson GM, Sloan CA, Casillas E. 1997. Fecundity and egg weight in English sole, Pleuromectes vetulus, from Puget Sound, Washington: Influence of nutritional status and chemical contaminants. Fish Bull 95:231-249.

Kareiva P, Marvier M, McClure M. 2000. Recovery and management options for spring/summer Chinook salmon in the Columbia River basin. Science 290:977-979.

Kime DE. 1999. A strategy for assessing the effects of xenobiotics on fish reproduction. Sci Total Environ 225:3-11.

Koztowski J. 1996. Optimal allocation of resources explains interspecific life-history patterns in animals with indeterminate growth. Proc $R$ Soc Lond B Biol Sci 263:559-566.

Kroglund F, Finstad B. 2003. Low concentrations of inorganic monomeric aluminum impair physiological status and marine survival of Atlantic salmon. Aquaculture 222:119-133.

Krümmel EM, MacDonald JA, Kimpe LE, Gregory-Eaves I, Demers MJ, Smol JP, Finney B, Blais JM. 2003. Aquatic ecology: Delivery of pollutants by spawning salmon. Nature 425:255-256.

Kurita Y, Meier S, Kjesbu OS. 2003. Oocyte growth and fecundity regulation by atresia of Atlantic herring (Clupea harengus) in relation to body condition throughout the maturation cycle. J Sea Res 49:203-219.

Laine P, Rajasilta M. 1999. The hatching success of Baltic herring eggs and its relation to female condition. J Exp Mar Biol Ecol 237:61-73.

Landahl JT, Johnson LL. 1993. Contaminant exposure and population growth of English sole in Puget Sound: The need for better early life-history data. Am Fish Soc Symp 14:117-123.

Matthiessen P, Law RJ. 2002. Contaminants and their effects on estuarine and coastal organisms in the United Kingdom in the late twentieth century. Environ Poll 120:739-757.

McCain BB, Malins DC, Krahn MM, Brown DW, Gronlund WD, Moore LK, Chan S-L. 1990. Uptake of aromatic and chlorinated hydrocarbons by juvenile Chinook salmon (Oncorhynchus tshawytscha) in an urban estuary. Arch Environ Contam Toxicol 19:10-16.

Milston RH, Fitzpatrick MS, Vella AT, Clements S, Gundersen D, Feist G, Crippe $T L$, Leong J, Schreck CB. 2003. Short-term exposure of Chinook salmon (Oncorhychus tschawystcha) to o, $p^{\prime}$-DDE or DMSO during early life-history stages causes long-term humoral immunosuppression. Environ Health Perspect 111:1601-1607.

Misitano DA, Casillas E, Haley CR. 1994. Effects of contaminated sediments on viability, length, DNA, and protein content of larval surf smelt, Hypomesus pretiosus. Mar Environ Res 37:1-21.

Peterman RM. 1980. Dynamics of Native Indian food fisheries on salmon in British Columbia. Can J Fish Aquat Sci 37:561-566.

[PSCCTC] Pacific Salmon Commission Chinook Technical Committee. 2002. Pacific Salmon Commission Joint Chinook Technical Committee Report: Annual exploitation rate analysis and model calibration. Vancouver (BC), Canada: PSCCTC. Report TCCHINOOK (02)-3.

Quinn TP, Peterson J, Gallucci V. 2000. Trends in adult coho and Chinook salmon life history at the University of Washington's hatchery. Draft annual report to Metro King County, Seattle (WA), USA.

Ratner S, Lande R, Roper BB. 1997. Population viability analysis of spring Chinook salmon in the South Umpqua River, Oregon. Conserv Biol 11:879889. 
Rice CA, Myers MS, Willis ML, French BL, Casillas E. 2000. From sediment bioassay to fish biomarker: Connecting the dots using simple trophic relationships. Mar Environ Res 50:527-533.

Roch M, McCarter JA. 1984. Metallotionein induction, growth, and survival of Chinook salmon exposed to zinc, copper, and cadmium. Bull Environ Contam Toxicol 32:478-485.

Roff DA. 1984. The evolution of life history parameters in teleosts. Can J Fish Aquat Sci 41:989-1000.

Roni P, Quinn TP. 1995. Geographic variation in size and age of North American Chinook salmon. N Am J Fish Manag 15:325-345.

Sabo JL, Holmes EE, Kareiva P. 2004. Efficacy of simple viability models in ecological risk assessment: Does density dependence matter? Ecology 85:328-341.

Santillo D, Stringer RL, Johnston PA, Tickner J. 1998. The precautionary principle: Protecting against failures of scientific method and risk assessment. Mar Pollut Bull 36:939-950.

Schaaf WE, Peters DS, Coston-Clement L, Vaughan DS, Krouse CW. 1993. A simulation model of how life history strategies mediate pollution effects in fish populations. Estuaries 16:697-702.

Scholz NL, Truelove NK, French BL, Berejikian BA, Quinn TP, Casillas E, Collier TK. 2000. Diazinon disrupts antipredator and homing behaviors in Chinook salmon (Oncorhynchus tshawytscha). Can J Fish Aquat Sci 57:1911-1918.

Sibly RM, Newton I, Walker CH. 2000. Effects of dieldrin on population growth rates of sparrowhawks 1963-1986. J App/ Ecol 37:540-546.

Sigler WF, Sigler JW. 1987. Fishes of the Great Basin. Reno (NV), USA: University Nevada Press.

Snell TW, Serra M. 2000. Using probability of extinction to evaluate the ecological significance of toxicant effects. Environ Toxicol Chem 19:2357-2363.

Stein JE, Hom T, Collier TK, Brown DW, Varanasi U. 1995. Contaminant exposure and biochemical effects in outmigrant juvenile Chinook salmon from urban and nonurban estuaries of Puget Sound, Washington. Environ Toxicol Chem 14:1019-1029.

Stephan CE, Mount DI, Hansen DJ, Gentile JH, Chapman GA, Brungs WA. 1985. Guidelines for deriving numerical national water quality criteria for the protection of aquatic organisms and their uses. Washington, DC: USEPA Office of Research and Development. EPA PB85-227049.

Suter II GW. 1993. Ecological risk assessment. Chelsea (MI), USA: Lewis.

Todd CR, Nicol SJ, Koehn JD. 2004. Density-dependence uncertainty in population models for the conservation management of trout cod, Maccullochella macquariensis. Ecol Model 171:359-380.

Trippel EA, Morgan MJ, Frechet A, Rollet C, Sinclair A, Annand C, Beanlands D, Brown L. 1997. Changes in age and length at sexual maturity of Northwest Atlantic cod, haddock and pollock stocks, 1972-1995. Canadian technical report of fisheries and aquatic sciences.

[USGS] U.S. Geological Survey. 1999. Pesticides detected in urban streams during rainstorms and relations to retail sales of pesticides in King County, Washington. Tacoma (WA): USGS. USGS Fact Sheet 097-99.

Varanasi U, Casillas E, Arkoosh MR, Hom T, Misitano DA, Brown DW, Chan S-L, Collier TK, McCain BB, Stein JE. 1993. Contaminant exposure and associated biological effects in juvenile Chinook salmon (Oncorhynchus tshawytscha) from urban and nonurban estuaries of Puget Sound. Seattle (WA): U.S. Dept Commerce, NOAA Tech Memo. NMFS-NWFSC-8.

Waples RS. 1991. Pacific salmon, Oncorhynchus spp., and the definition of "species" under the Endangered Species Act. Mar Fish Rev 53:11-22.

West CJ, Larkin PA. 1987. Evidence of size-selective mortality of juvenile sockeye salmon (Oncorhynchus nerka) in Babine Lake, British Columbia. Can J Fish Aquat Sci 44:712-721.

Wootton RJ. 1992. Constraints in the evolution of fish life histories. Neth J Zool 42:291-303. 